\title{
Modeling Microfibril Angle and Tree Age in Acacia Mangium Wood Using X-Ray Diffraction Technique
}

\author{
Tamer A. Tabet, Fauziah Abdul Aziz, and Noraini Abdulla
}

\begin{abstract}
The objective of this research is to suggest a regression models on the age-affecting and microfibril angle in Acacia mangium wood. Farther objective is to estimate the optimum age which produce fully crystalline cellulose in Acacia mangium wood. The term microfibril angle (MFA) in wood refers to the angle between the spiralling cellulose fibrils and the long axis of the tracheid cell wall. Acacia mangium wood was chosen for experimental data. In this study, the main MFA of the cell walls were determined for thin samples of thickness $200 \mu \mathrm{m}$ from pith and outwards, for eight ages of Acacia mangium wood. The determination of MFA was based on diffraction pattern arising from cellulose crystal planes of the type 002 generated by $x$-ray diffraction and recorded using an electronic detector. Age-contributing factors were measured; the diffraction angle $(2 \theta)$, relative intensity, full width at half maximum (FWHM), the nearest between two neighbouring atoms in the crystalline structure (d-spacing) and the peak height, had been taken into account at different ages, pith and bark of tree. Regressions were done in comparing the microfibril angle, MFA at different ages using the least-square method and cubic-spline interpolation. The latter was able to interpolate a polynomial up to the third order. The range of the optimum angle was found to have benefited foresters in deciding the time for tree cropping and harvesting. The results show that comparisons of linear polynomials for Acacia mangium at different tree ages had shown that the MFA varies according to age with a small mean and variance. Using the LS method, the regression equations of the grain size as corresponds to the regions of the trunk, gave an optimal fit of $\mathrm{R} 2>0.87$, indicating a strong positive relationship. It was found that the cellulose crystalline has grown fully at $a o$ about $23.0 \pm 0.5$ year for completely studied tree age.
\end{abstract}

Index Terms - Crystallographic factors, regression model, interpolation, microfibril angle, optimum angle.

\section{INTRODUCTION}

The orientation of the cellulose microfibrils in the S2 layers of the cell walls of softwood has a significant influence on the mechanical properties of wood. The angle between the cellulose fibrils and the longitudinal cell axis, the microfibril angle, MFA was found to be a critical factor in determining the physical and mechanical properties of wood (Cave, 1997). For this reason, considerable effort has been directed towards the measurement of the cellulose MFA. Direct measurement of MFA has been made by highlighting microfibrils in individual cell walls with iodine staining, but the most widely adopted techniques use either wide-angle X-ray diffraction or small-angle X-ray scattering The pioneering work of Cave (1976) and Meylan (1967) led to the use of the ' $T$ ' parameter derived from the curve distribution of the intensity diffracted by the (002) planes of the cellulose fibrils.

MFA had a significant impact on wood quality and paper properties; smaller angles were associated with high tensile strength while larger angles were associated with larger stretch and tear indices. It was also known to be inversely related to fiber length, with longer fibers having smaller angles (Donaldson, 1993). Wood stiffness was found to be influenced by MFA which arose from the cellulose content (Walker and Butterfield, 1996; Cave and Walker, 1994). Young trees and branches would feature high MFAs while older trees would have low MFAs indicating maximum stiffness (Mary et al., 2001) and Tamer et al., 2009).

\section{MATERIALS AND METHODS}

\section{A. Data collection}

The wood samples used in this study were selected from 3, 5, 7, 9, 10, 11, 13 and 15 year-old of Acacia mangium tree from Sabah Forestry Development Authority (SAFODA). The standard methodology for the physical characterization followed the International technical standard (ISO standard 4471-1982). The samples were taken out at breast height $(1.25 \mathrm{~m})$ on each tree. An x-ray diffractometer (Philips X-Pert PRO PW3040/60) was used to determine the average microfibril angle. A point-focused $\mathrm{x}$-ray beam $(\mathrm{Cu}-\mathrm{K} \alpha$ x-ray, beam diameter $1 \mathrm{~mm})$ was applied to tangential section, $200 \mu \mathrm{m}$ thick $\mathrm{x} 2 \mathrm{~mm}$ long, prepared from the pith and bark regions with a sliding microtome as shown in Fig. 1.

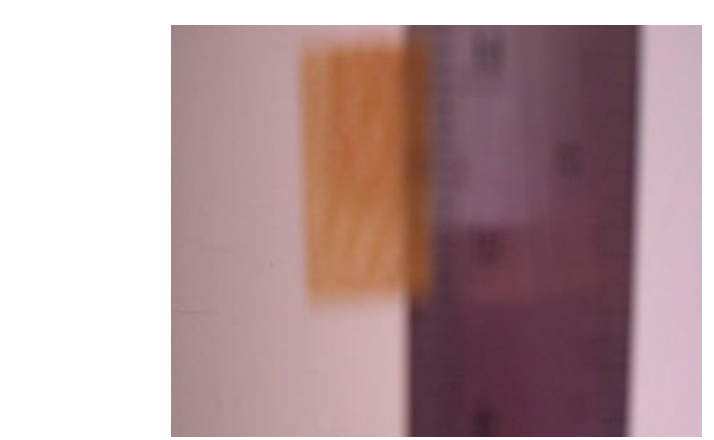

(a)
Manuscript received May 9, 2012; revised June 12,2012

T. A. Tabet is with the School of International Tropical Forestry, Universiti Malaysia Sabah, 88400, Kota Kinabalu, Sabah, Malaysia (email: tamertbt@ums.edu.my).

F. A. Aziz is with Physics Department, Centre for Defence Foundation Studies, National Defence University of Malaysia (NDUM), Kem Sg. Besi 57000 Kuala Lumpur, Malaysia (e-mail: afauziah@upnm.edu.my).

N. Abdulla is with the Mathematics with Economics Programme, School of Science and Technology, Universiti Malaysia Sabah, 88400 Kota Kinabalu, Sabah (e-mail: noraini@ums.edu.my). 


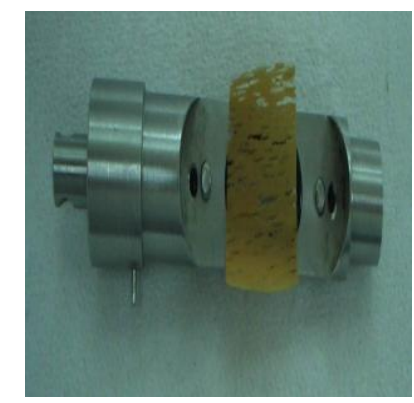

(b)

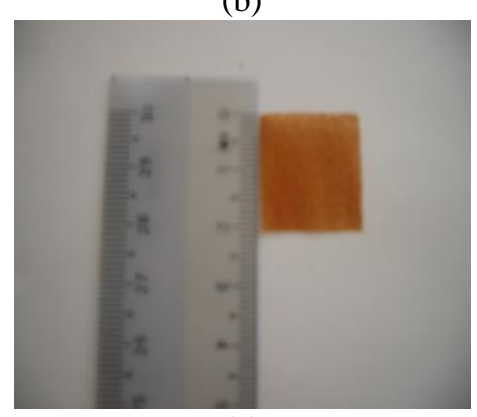

(c)

Fig. 1. Thin samples of Acacia mangium for XRD test and SEM observation.

\section{B. Experimental Calculations}

The MFA is determined from the intensity that has the strongest peak as shown in Fig. 2. The intensity peak is used to calculate the parameter $\mathrm{T}$ for all growth ages because the peak of the diffraction intensity gives the best Full Width Half Maximum (FWHM). MFA in the secondary layer of the cell wall was estimated from the FWHM for each reflection using Meylan's formula (Meylan, 1967). The FWHM is related to the intensity and can be related to the parameter $\mathrm{T}$ as in equation 1 :

$$
F W H M=\sqrt{2 \ln (2) T}=1.1774 T
$$

This formula was further developed by Cave (1997) to calculate the value of $T$ and hence, MFA using the Meylan's formula.

$$
\mathrm{MFA}=0.6 T \quad=1.9623 \mathrm{FWHM}
$$

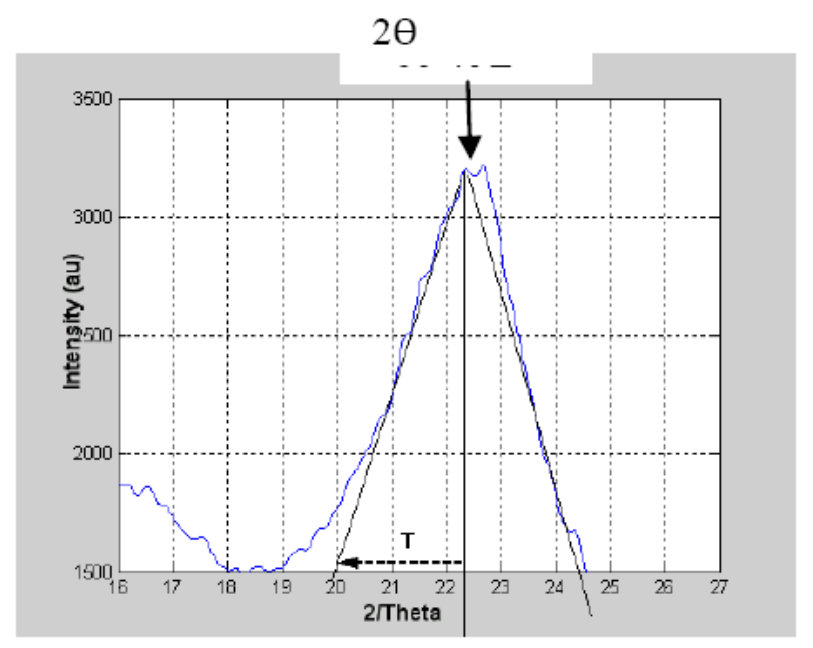

Fig. 2. X-ray diffraction intensity used to measure the parameter $\mathrm{T}$ in the pith of wood model of 3-year old.

\section{Linear Regression (LR) Using the Least-Square (LS) Method}

Linear regression models using LS method is used to model numerical data obtained from observations so as to get an optimal fit of the data by minimizing the sum of the square of the residuals. The strength of association between the variables is measured by the Pearson correlation coefficient, $r$ as given by (3):

$$
r=\frac{\sum_{i=1}^{n} X_{i} Y_{i}-\frac{\sum_{i=1}^{n} X_{i} \sum_{i=1}^{n} Y_{i}}{n}}{\sqrt{\left(\sum_{i=1}^{n} X_{i}^{2}-\frac{\left(\sum_{i=1}^{n} X_{i}\right)^{2}}{n}\right)\left(\sum_{i=1}^{n} Y_{i}^{2}-\frac{\left.\left(\sum_{i=1}^{n} Y_{i}\right)^{2}\right)}{n}\right)}}
$$

where $X, Y=$ the variables that are being compared, $n=$ sample size

Linear regression model (2) is thus used to regress the amount of the criterion variable with respect to the manipulation of the amount or values of the regressor variables as given by :-

$$
Y_{i}=\alpha+\sum_{i=1}^{k} \beta_{i} \cdot X_{i}
$$

where $Y i=$ the MFA of the Acacia mangium wood, $\alpha=$ the intercept, $\beta i=$ the parameter coefficients for the regressor, $\mathrm{k}=$ the number of regressors, $\mathrm{X} 1, \mathrm{X} 2, \mathrm{X} 3=$ the regressor variables.

The proportion of the total variability in MFA, Y, attributable to the dependence of $\mathrm{Y}$ on all the regressors would be measured by the adjusted coefficient of multiple determinations (5), $R_{a}^{2}$.

$$
R_{a}^{2}=1-\frac{M S E}{M S(\text { Total })}
$$

where MSE = mean sum of squares of error, MS (Total) $=$ mean sum of squares of total.

\section{RESULTS}

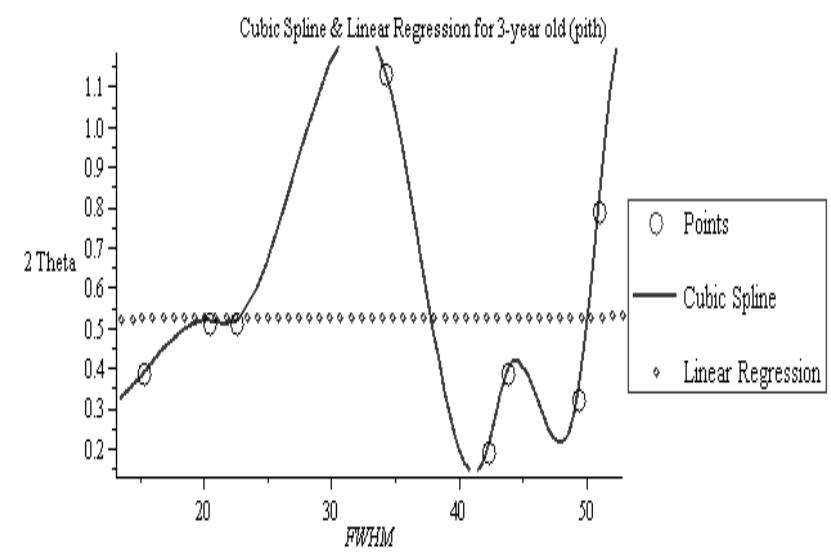




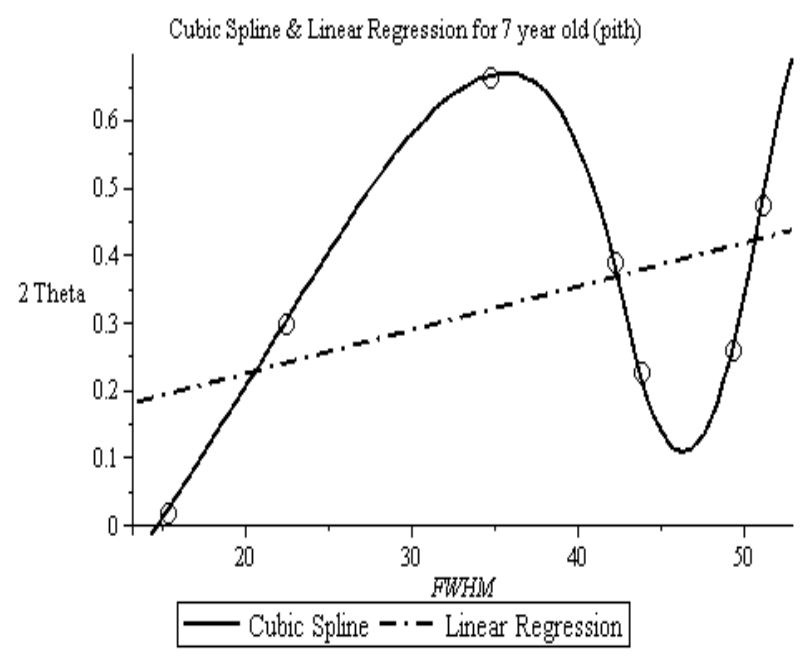

Fig. 3. Cubic splines and linear regressions for 3 and 7 year-old trees.
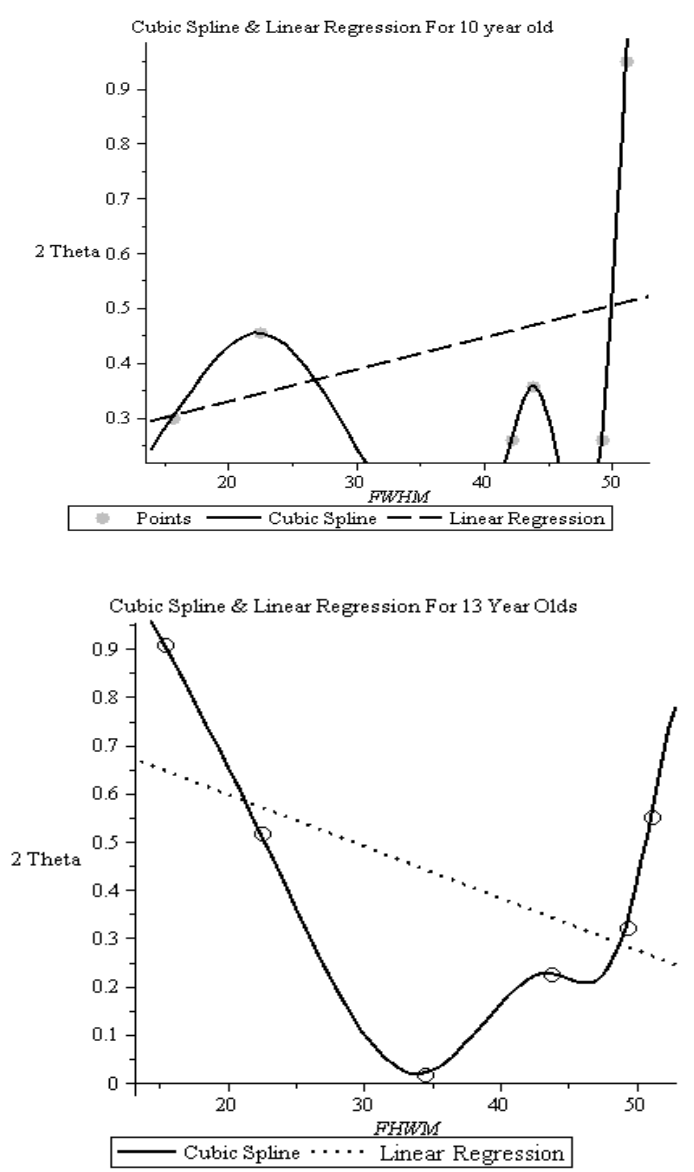

Fig. 4. Cubic splines and linear regressions for 10 and 13 year-old trees.

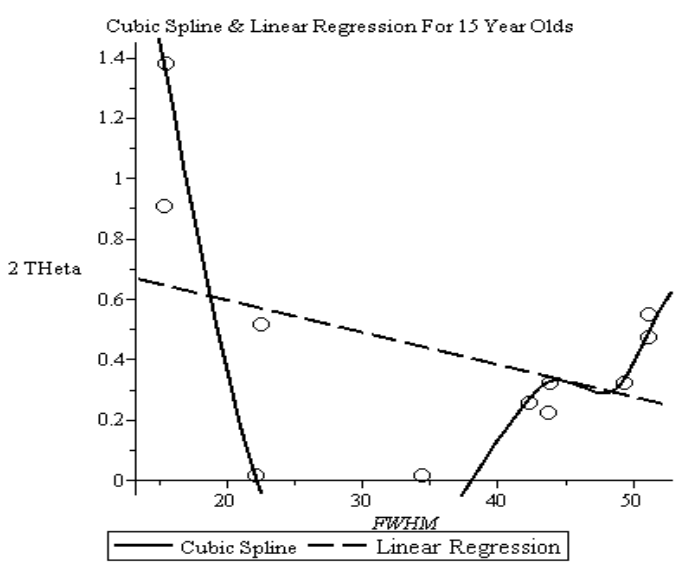

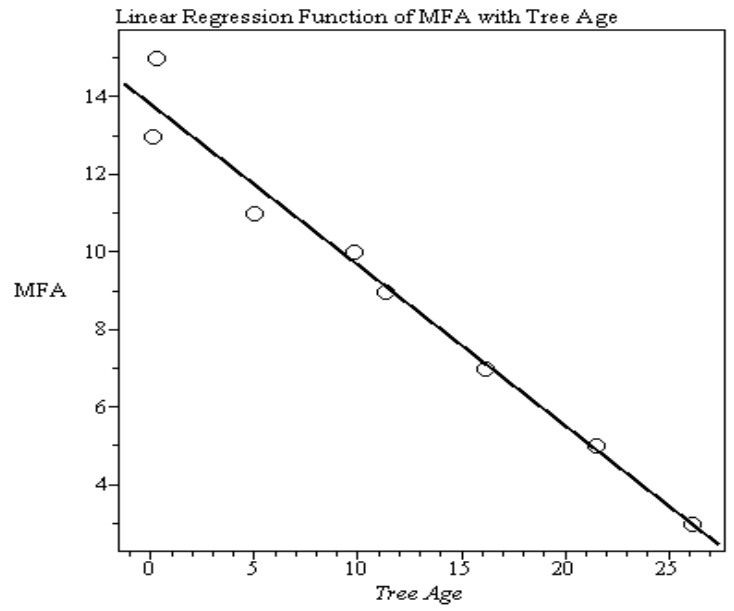

Fig. 4. Cubic spline and linear regression for 15 year-old and simple linear regression of MFA versus Tree Age.

Comparisons of linear polynomials for Acacia mangium at different tree ages had shown that the MFA varies according to age with a small mean and variance. Using the LS method also, the regression equations of the grain size as corresponds to the regions of the trunk, gave an optimal fit of $\mathrm{R}^{2}>0.87$, indicating a strong positive relationship. The cubic splines since passing through all the observed data, practically gave a zero error distribution. However, the polynomial structure thus observed was able to indicate that as the trees mature in age, the intercept of the LR models approached the value of 1. MFA versus Age of Trees also gave a simple linear regression equation of $y=13.7915-$ $0.41477 \mathrm{x}$, showing that the microfibril angle decreases in size as the trees mature in age.

Using LS method, however, the regression equations of Full Width Half Maximum versus Age of trees were given below in Table I:

TABLE I: REGRESSION EQUATIONS ACCORDING TO AGE, GRAIN SIZE AND REGION OF WOOD

\begin{tabular}{|l|l|l|l|}
\hline $\begin{array}{l}\text { Grain } \\
\text { Size }\end{array}$ & $\begin{array}{l}\text { Regression Eqn (FWHM vs } \\
\text { Age of Tree) }\end{array}$ & $\mathrm{R}^{2}$ & Region \\
\hline 63.0 & $\mathrm{Y}=23.446-25.292 \mathrm{x}$ & 0.9044 & pith \\
\hline 63.0 & $\mathrm{Y}=23.292-21.385 \mathrm{x}$ & 0.9875 & bark \\
\hline 63.0 & $\mathrm{Y}=22.924-21.634 \mathrm{x}$ & 0.9097 & Pith-bark \\
\hline 150.0 & $\mathrm{Y}=23.029-29.195 \mathrm{x}$ & 0.8759 & pith \\
\hline 150.0 & $\mathrm{Y}=23.194-29.856 \mathrm{x}$ & 0.9499 & bark \\
\hline 150.0 & $\mathrm{Y}=22.781-28.157 \mathrm{x}$ & 0.9567 & Pith bark \\
\hline
\end{tabular}

\section{DISCUSSION AND CONCLUSION}

Third-order polynomials or cubic splines are frequently used in modelling practical problems. Employment of these models is less expensive in terms of time and/or money after identifying its structure for estimation and prediction. It is recommended that further research into MFA, hardness, density and intensity can be expounded which in turn can also be modelled, using other models such as the Generalized Linear Models (GLM) for simplicity.

\section{REFERENCES}

[1] I. D. Cave, "Theory of X-Ray Measurement of Microfibril Angle in Wood. Part 1. The Condition for Reflection. X-Ray Diffraction by Materials with Fibre Type Symmetry," Wood Science and Technology, vol. 31, no. 3, pp.143-152, 1997. 
[2] I. D. Cave, "Modeling the Structure of the Softwood Cell Wall for Computation of Mechanical Properties," Wood Science and Technology, vol. 10, pp. 19-28, 1976.

[3] I. D. Cave and J. F. C. Walker, "Stiffness of Wood in Farown Plantation Softwood: The Influence of Microfibril Angle," Forest Product Journal, vol. 44, no. 5, pp. 43-48.

[4] L. A. Donaldson, "Variation in Microfibril Angle among Three Genetic Groups of Pinus radiate," New Zealand Journal of Forestry Science, vol. 25, no. 2, pp. 164-174, 1993.

[5] M. Mary Tracy, "A Comparison of Mechanical and Physical Wood Properties of a Range of Sitka spruce Provenances," Processing
Products No.1 Extract from Coford final report publication. Coford, Diblin, Ireland. 2001, pp. 37-51.

[6] A. B. Meylan, "Measurement of Microfibril Angle by X-Ray Diffraction," Forest Prod. Journal, vol. 17, pp. 15-58, 1967.

[7] A. Tamer and F. Aziz, "Influence of Microfibril Angle on Thermal and Dynamic-Mechanical Properties of Acacia mangium Wood Using X-Ray Diffraction and Dynamics-Mechanical Test," Journal of Nuclear and Related Technologies, vol. 6, no. 1, pp. 71-86, 2009.

[8] J. C. F. Walker and B. G. Butterfield, "The Importance of Microfibril Angle for the Processing Industries," New Zealand Forestry, pp. 30-40, Feb. 1996. 